\title{
INSERÇÃO SOCIAL DA CRIANÇA PORTADORA DE NECESSIDADES ESPECIAIS: A PERSPECTIVAMATERNA
}

\author{
Viviane Marten Milbrath ${ }^{1}$, Deise Cardoso Soares ${ }^{2}$, Diana Cecagno ${ }^{3}$, Simone Coelho Amestoy ${ }^{4}$, Hedi Crecencia Heckler \\ de Siqueira ${ }^{5}$
}

RESUMO: Frente à relevância da inserção social da criança portadora de necessidades especiais no seu processo de crescimento e desenvolvimento, objetivou-se com esse estudo conhecer como a mulher/mãe percebe a inserção social de seu filho portador de necessidades especiais decorrentes do diagnóstico da paralisia cerebral. Pesquisa exploratóriadescritiva com abordagem qualitativa. Os dados foram coletados, por meio de entrevistas semi-estruturadas, com as mães de crianças que frequentam uma instituição que atende crianças portadoras de necessidades especiais. A análise dos dados apontou algumas dificuldades encontradas em relação à inserção social da criança num ambiente maior que o intrafamiliar, com destaque para: locomoção e inserção nos grupos sociais como, por exemplo, a escola. Concluímos que as principais dificuldades encontradas estão relacionadas às políticas públicas de acesso e inserção, compreendemos que cabe ao enfermeiro como promotor da saúde incentivar e comprometer estas famílias no resgate da cidadania.

PALAVRAS-CHAVE: Crianças portadoras de deficiência; Socialização; Enfermagem.

\section{SOCIAL INTEGRATION OF CHILD WITH SPECIAL NEEDS: THE MATERNAL PERSPECTIVE}

\begin{abstract}
Facing the importance of social inclusion of child with special needs in their process of growth and development, with this study we aimed to known how the woman/mother perceives the social inclusion of their child with special needs which came along with the diagnosis of cerebral palsy. It's an exploratory-descriptive research with a qualitative approach. Data were collected through semi-structured interviews with mothers of children who attend an institution that cares for children with special needs. Data analysis pointed out some difficulties regarding to the social inclusion of a child in an environment larger than the family one, with emphasis on: mobility and integration in social groups, such as school. We concluded that the main difficulties are related to public policies for access and inclusion; we understand the nurse's role as promoter of health, who has to encourage and encourage these families in recovering their citizenship.

KEYWORDS: Disabled children; Socialization; Nursing.

\section{INCLUSIÓN SOCIAL DEL NIÑO PORTADOR DE NECESIDADES ESPECIALES: LA PERSPECTIVAMATERNA}

RESUMEN: Frente a la importancia de la inclusión social del niño portador de necesidades especiales en su proceso de crecimiento y desarrollo, se objetivó con este estudio, conocer como la mujer/madre percibe la inclusión social de su hijo portador de necesidades especiales derivadas del diagnóstico de la parálisis cerebral. Investigación exploratoria-descriptiva con abordaje cualitativo. Los datos fueron recolectados, a través de entrevistas semiestructuradas, con las madres de los niños que frecuentan una institución que atiende a niños con necesidades especiales. El análisis de los datos mostró algunas dificultades encontradas en relación a la inclusión social de los niños en un entorno mayor que el intrafamiliar, con énfasis en: la locomoción e inclusión en los grupos sociales, tales como la escuela. Concluimos que las principales dificultades encontradas están relacionadas con las políticas públicas de acceso e inclusión, entendemos que cabe al enfermero, como promotor de la salud, incentivar y comprometer estas familias en el rescate de la ciudadanía.

PALABRAS CLAVE: Niños portadores de deficiencia; Socialización; Enfermería.

\footnotetext{
${ }^{1}$ Enfermeira. Mestre em Enfermagem pela Fundação Universidade Federal do Rio Grande-FURG-RS. Membro do Núcleo de Estudos e Pesquisa: Gerenciamento Ecossistêmico em Enfermagem/Saúde-GEES.

${ }^{2}$ Enfermeira. Mestre em Enfermagem pela FURG. Membro do Núcleo de Pesquisa GEES

${ }^{3}$ Enfermeira. Mestre em Enfermagem pela FURG. Membro Vice-Líder do Núcleo de Pesquisa GEES.

${ }^{4}$ Enfermeira. Mestre em Enfermagem pela FURG

${ }^{5}$ Enfermeira. Mestre e Doutora em Enfermagem. Docente do Programa de Pós Graduação em Enfermagem da FURG. Membro do Núcleo de Pesquisa GEES.
}

Autor correspondente:

Viviane Marten Milbrath

Rua Major Francisco Nunes de Souza, 4316 - 96045-000 - Pelotas - RS

E-mail: vivimarten@ig.com.br 


\section{INTRODUÇÃO}

O processo de crescimento e desenvolvimento infantil compreende várias etapas e em cada uma delas ocorre um acréscimo de experiências e vivências que interferem na sua formação. Esse processo encontra-se atrelado a múltiplos fatores, destacandose os biológicos e sociais, que repercutem positiva e/ ou negativamente no desenvolvimento da criança ${ }^{(1)}$.

Considera-se a família um dos principais ambientes responsáveis pela criança, pois é ela quem possibilita condições necessárias para o seu crescimento e desenvolvimento fisiológico, intelectual, psicológico e social ${ }^{(2-3)}$. Entretanto, essa família pode atuar estimulando ou expondo a criança a situações de riscos ${ }^{(4)}$, visto que o processo de crescimento e o desenvolvimento dependem em grande parte dos cuidados recebidos durante a primeira infância. A atenção às necessidades vitais como alimentação, estimulação, compreensão, afeto e cuidado, principalmente, nos primeiros anos de vida, é considerada garantia de que a criança terá oportunidades para crescer e se desenvolver adequadamente, superando por vezes suas próprias potencialidades $^{(5)}$.

Sob essa ótica a família é percebida como uma unidade de referência, que está sendo revalorizada na sua função socializadora, sofrendo determinações de ordem sócio-econômica-política, cultural e religiosa e, ao mesmo tempo, determinante de subjetividade de sentimentos como amor, afeto, exercício de poder, raiva, limites. Assim sendo, é considerada como fator decisório para promoção, manutenção da saúde e qualidade de vida das pessoas que a compõem ${ }^{(3)}$. Pode-se dizer que indiferentemente da sua estrutura, a família mantém-se como principal meio para estimular as relações da criança com o mundo(6).

Mesmo naquelas crianças em que há uma ruptura do que se considera um processo de desenvolvimento e crescimento "normal”, a família constitui o primeiro universo de relações sociais ${ }^{(2)} \mathrm{e}$ acredita-se que o núcleo familiar é o local onde ocorre a formação da base da auto-estima e dignidade humana, valores necessários para a criança enfrentar os desafios do mundo social ${ }^{(7)}$.

Nesse sentido, as relações sociais estabelecidas no microssistema familiar são consideradas as que trazem implicações mais significativas para o desenvolvimento da criança, embora autores também concordem que outros sistemas sociais como a escola, clube, igreja, são contribuintes no processo do desenvolvimento infantil ${ }^{(8)}$.

A inserção da criança na sociedade pode ser prejudicada quando ela for portadora de uma necessidade especial que lhe cause dano motor ou cognitivo. Nesse sentido, a família pode ser um instrumento decisivo na inclusão social da criança. Dentre os ambientes sociais considerados capazes de contribuir para o desenvolvimento infantil encontra-se a escola que, igualmente à família, é considerada local formador de pensamentos e de ajustes psicossociais e espirituais.

A criança ao ingressar na escola ${ }^{(9)}$ começa a fazer parte de um grupo maior e o seu relacionamento com colegas, professores e outros funcionários, ajudará no desenvolvimento de auto-conceito e auto-estima, o que representa uma mudança profunda em suas relações, precisando para tanto ser aceita pelos colegas e professores ${ }^{(10)}$. Entretanto, mesmo a escola sendo considerada fundamental para o desenvolvimento e socialização da criança muitas vezes pode ser apontada como uma fonte de discriminação ${ }^{(10)}$.

Frente à relevância da inserção social da criança portadora de necessidades especiais no seu processo de crescimento e desenvolvimento objetivou-se com esse estudo conhecer como a mulher/mãe percebe a inserção social de seu filho portador de necessidades especiais decorrentes do diagnóstico da paralisia cerebral.

\section{METODOLOGIA}

Para a realização deste estudo utilizou-se uma metodologia descritiva e exploratória, à luz de uma abordagem qualitativa. É qualitativa enquanto busca incorporar o significado e a intencionalidade dos atos das mulheres-mães de crianças portadoras de paralisia cerebral, conhecendo as relações e as estruturas sociais capazes de fornecer apoio no processo de adaptação. Portanto, trabalha com os significados, motivos, aspirações, crenças, valores e atitudes, em constante transformação $0^{(11)}$.

O projeto de pesquisa foi aprovado pelo Comitê de Ética em Pesquisa da Universidade Federal de Pelotas, sob o n. 045/06. Após o aceite formal da instituição, os sujeitos foram contatados e convidados a participarem do estudo. Todos aceitaram e se colocaram à disposição para colaborar com o trabalho, diante disso foi agendada uma entrevista. Ao expor a proposta, foi solicitado por escrito, conforme a Resolução n. 196/96 
do Conselho Nacional de Saúde, o Consentimento Livre e Esclarecido dos participantes, assinado em duas vias, ficando uma com o participante e outra com o pesquisador responsável. Foram enfatizados os aspectos legais e éticos envolvidos e a liberdade de desistência a qualquer momento, se assim desejassem, sem nenhum prejuízo pessoal. Foi garantido também o anonimato e o sigilo. Os dados coletados ficaram sob a guarda do pesquisador responsável.

A escolha dos sujeitos foi realizada de forma aleatória entre mulheres-mães de crianças portadoras de paralisia cerebral que freqüentavam uma instituição que atende crianças portadoras de necessidades especiais num município do Rio Grande do Sul. Todas as convidadas aceitaram participar da pesquisa. A delimitação do número de sujeitos observou a saturação dos dados ${ }^{(11)}$, ou seja, o prosseguimento das entrevistas ocorreu enquanto surgiram dados novos, e as mesmas foram suspensas no momento em que os dados se tornaram repetitivos, perfazendo um total de seis mulheres-mães, identificadas com o pseudônimo mãe 1 , mãe 2 [...] mãe 6.

Os dados foram coletados no período de julho a setembro de 2006 por meio de uma entrevista semiestruturada, com permissão de sua gravação por todos os sujeitos envolvidos. De posse dos dados, optou-se em analisá-los através da análise temática, que consiste nas etapas: pré-análise, exploração dos dados, tratamento dos resultados obtidos e interpretação ${ }^{(8)}$. Na pré-análise, os dados coletados foram transcritos na íntegra. A seguir foram realizadas leituras e releituras flutuantes com a finalidade de tomar contato exaustivo com as informações coletadas.

Prosseguindo, procedeu-se a organização dos dados transcritos destacando os aspectos relevantes. Após esta etapa, realizou-se o mapeamento das falas das entrevistas, assinalando os principais pontos de cada fala, para facilitar a visualização do material como um todo.

Na etapa de exploração dos dados foram identificadas as unidades de registro com a realização dos recortes necessários. Novas leituras foram desenvolvidas, buscando apreender o significado manifesto e/ou oculto das observações e informações contidas nos relatos, encaminhando a novas reflexões para agrupar os dados e estabelecer as categorias.

\section{INTERPRETAÇÃO DAS INFORMAÇÕES}

Em relação ao tema proposto e após a interpretação das informações, emergiram duas categorias temáticas: A dificuldade de locomoção e A escola: um ambiente de socialização?

\section{A dificuldade de locomoção:}

Os depoimentos das mães das crianças portadoras de necessidades especiais decorrentes do diagnóstico da paralisia cerebral demonstraram que a dificuldade na locomoção é considerada uma problemática extremamente complexa, que interfere significativamente na integração da criança com um meio ambiente maior que o intrafamiliar, com destaque para a escola:

A locomoção agora tá ficando difícil, porque ele tá crescendo e ficando pesado para ficar o tempo todo no colo, mas às vezes eu saio com ele no colo, e outras vezes no carrinho, estamos tentando comprar uma cadeira de rodas [...] mas por enquanto apesar da dificuldade ele só tem 3 anos mas, daqui em diante eu sinceramente não sei como vai ser (Mãe 2).

A Mãe 2 expressa seu receio com o futuro, visto que a dificuldade de locomoção se acentua conforme o crescimento da criança. Situação semelhante é descrita pela Mãe 4:

Agora ele quer uma cadeira de rodas, pois ele acha que com ela ele vai se tornar independente de mim, ou seja, ele vai conduzir a cadeira, entendeu, mas eu tento explicar que as coisas não são assim, $e$ que ele vai continuar dependendo de mim, pois não consegue ter coordenação para conduzir a cadeira (Mãe 4).

As Mães 2 e 4 expressam seus medos quanto ao futuro de seus filhos. A Mãe 4 refere também, sua preocupação em relação a dependência do filho para realizar as ações do dia-a-dia, em decorrência da incoordenação motora.

Os depoimentos que seguem expressam certa "revolta/dúvida" pela ausência de infra-estrutura urbana adequada para aqueles que possuem alguma dificuldade motora:

A locomoção, eu acho assim que a prefeitura deveria colocar mais ônibus de cadereirante, porque isso facilitaria muito não só para o PC, 
mas para qualquer deficiente, e isso na minha opinião está deixando muito a desejar (Mãe 2).

Deveria ter mais ônibus para deficiente, daqueles que dá prá entrar com a cadeira de rodas, pois isso ia ajudar muito, os degraus nas calçadas também são um [...], pois o percurso cansa muito $e$ às vezes a gente fica desanimado (Mãe 3).

Ir prá qualquer lugar tá mais difícil, porque ele tá muito pesado prá gente carregar, e sair com a cadeira de rodas, é complicado porque os ônibus para os cadeirantes são raros (Mãe 6).

Ao refletir sobre as falas das Mães 2, 3 e 6 percebe-se que a busca para a inclusão social das pessoas portadoras de necessidades especiais esbarra por vezes em obstáculos que poderiam ser resolvidos com iniciativas do governo e da sociedade privada, mediante o comprimento da legislação já existente e elaboração de novos procedimentos legais. Muitas vezes a demanda ambiental dificulta ou facilita consideravelmente a vida das pessoas, principalmente daquelas que portam uma necessidade especial ${ }^{(12)}$.

$\mathrm{O}$ artigo $16^{\circ}$ do Estatuto da Criança e do Adolescente-ECA ${ }^{(13)}$ preconiza que a criança e o adolescente, indiferentemente da raça, crença, sexo, dificuldades motoras ou mentais, têm o direito de ir e vir, de brincar, de compartilhar da vida familiar e comunitária, sem discriminação, de participar também da vida política, na forma da lei. Na vivência cotidiana, alguns destes direitos são inviabilizados, pois vivemos em cidades desprovidas de infra-estrutura para atender aqueles que possuem alguma dificuldade de locomoção. Entre as deficiências da infra-estrutura destacamos: as calçadas sem rampas, ruas com buracos e desníveis, semáforos sem sinais sonoros, prédios sem elevador, além de escassez de transporte público com dispositivos para cadeirantes. Essas temáticas, ao se tornarem parte da rotina diária, começam a passar de forma despercebida por aqueles considerados "normais", ou seja, aos que não tem agredido o seu direito de ir e vir permeando indiretamente a exclusão social. Os portadores de diversas necessidades especiais são vulnerabilizados pela indiferença da sociedade dita “normal” e pela ausência de políticas públicas, capazes de viabilizar a inclusão social.

A Mãe 3, ao dizer que chega a se sentir desanimada, permite constatar a necessidade dessas famílias de possuírem uma rede de apoio na qual possam buscar alternativas para diminuir seus medos e anseios, encontrar soluções que visem a minimização das dificuldades advindas das necessidades especiais decorrentes da paralisia cerebral e, por conseguinte, a melhoria da qualidade de vida para a criança e a própria família.

\section{A escola: uma ambiente de socialização?}

A inclusão social trata do respeito às diferenças, dos direitos e da participação igualitária de cada cidadão. No caso das crianças portadoras de necessidades especiais a inclusão social abrange como um dos seus principais pontos a inclusão escolar ${ }^{(14)}$, inserindo a criança com necessidades especiais na rede regular de ensino.

Na idade escolar a criança passa a formar grupos de acordo com a idade e o sexo, onde aprende sobre estruturas formais, sejam autoritárias ou democráticas, sobre o líder e os liderados

Vale ressaltar que dependendo do seu potencial cognitivo, da capacidade de aprendizagem, uma criança com paralisia cerebral pode estar apta à escola regular de ensino, em classe compatível com a sua faixa etária ${ }^{(15)}$.

Cursar uma escola de ensino regular possibilita à criança portadora de necessidades especiais uma convivência com outras crianças. De modo geral, pode-se dizer que o fator de maior significância desta interação consiste no fato de permitir às crianças o convívio com diferenças étnicas, sociais, comportamentais e físicas, que devem ser respeitadas. Provavelmente, não existe na vida humana período melhor que a infância para se trabalhar na construção de uma consciência crítica e reflexiva, com princípios permeados pela igualdade e pela dignidade ${ }^{(16)}$.

A Mãe 1 refere em seu depoimento que foi orientada por uma instituição que atende pessoas portadoras de necessidades especiais a colocar seu filho na rede regular de ensino, o que nos faz refletir em uma possível carência de instituições de apoio na região.

Foi lá no Sara em Brasília que me disseram que ele podia ir para um colégio normal, assim de crianças normais (Mãe 1).

Cooperando com o processo de inclusão das pessoas portadoras de deficiência ${ }^{(17)}$, o Estatuto enfatiza que as escolas de ensino regular, tanto públicas como privadas, têm obrigação de aceitar portadores 
de deficiência, desde que eles tenham capacidade de acompanhar o ensino regular. Porém, se olharmos para essa questão da "capacidade" de uma forma mais crítica, percebemos que ela se encontra atrelada a questões como o preparo dos educadores, as diretrizes pedagógicas e a própria acessibilidade física; o que destitui a questão naturalizada de que a criança "capaz” poderá ser incluída nas instituições regulares de ensino. Emerge deste contexto outra situação: o que está sendo disponibilizado para que a criança portadora de necessidades especiais tenha acesso à educação?

Nota-se na fala da Mãe 1 que essas crianças enfrentam "preconceito" ao ingressarem na rede regular de ensino.

A educação dele, ele já tá no colégio, mas no primeiro colégio que encontramos para ele, assim, num primeiro momento eles aceitaram ele, mas logo depois eles começaram a botar um monte de empecilhos e nós tivemos então que procurar outro colégio para ele (Mãe 1).

Ao refletir sobre a fala da Mãe 1, pode-se considerar sua frustração frente a não aceitação de seu filho na instituição. Durante a entrevista foi possível observar sua face de alegria ao referir que uma instituição respeitada como o Sarah Kubtscheck orientou-a no sentido de que seu filho era "capaz" de ingressar na rede regular de ensino e, alguns minutos após, era visível a expressão de tristeza ao relatar a rejeição da escola procurada.

Conforme os artigos $53^{\circ}$ e $54^{\circ}$ do $\mathrm{ECA}^{(13)}$, é direito da criança que a educação vise seu pleno desenvolvimento como pessoa, preparando-a para o exercício da cidadania, garantindo atendimento educacional especializado aos portadores de necessidades especiais, preferencialmente, na rede regular de ensino.

Entretanto, a inclusão social da criança portadora de necessidades especiais por meio da escola mostra-se quase utópica diante da realidade ${ }^{(12)}$. Na educação brasileira as escolas geralmente são desprovidas de estrutura física adequada e recursos humanos especializados para atender essa demanda. Existem pesquisas que confirmam que mesmo quando as escolas são projetadas ou reformadas com a preocupação da inclusão social muitas vezes não são construídas adequadamente por falta de conhecimento das especificidades ${ }^{(12)}$.

A inclusão escolar pressupõe mudanças físicas e comportamentais relacionadas a posturas frente às concepções que co-habitam na escola. Um dos embates de maior significância no ambiente escolar é o que se refere à formação dos professores para compreensão dos cuidados necessários à criança portadora de necessidades especiais ${ }^{(18)}$. É primordial encontrar alternativas para atender a esse grupo de crianças e assim, apoiar as famílias e as crianças a fim de que não se sintam marginalizadas pela sociedade.

Ela ainda não vai pro colégio [...] mas sabe eu tenho assim, medo de que quando ele for os coleguinhas fiquem debochando dela, pelo problema motor né, tu sabe como é criança [...] (Mãe 3).

Não vejo meu filho como um "retardado", pois ele entende tudo, ele é inteligente, os médicos mesmo me dizem que ele não tem um problema mental, de inteligência, o problema dele, eles mesmos dizem é motor, então eu não entendo, porque que nas escolas os professores, não veem isso (Mãe 6).

A Mãe 3 refere o seu receio com relação ao enfrentamento que sua filha terá em um novo ambiente, no qual os integrantes, muitas vezes, não estão acostumados com as diferenças. No mesmo contexto, a Mãe 6 desabafa e questiona o despreparo das escolas regulares de ensino para atender crianças portadoras de necessidades especiais. A falta de estrutura física e humana das escolas gera uma inquietude no que se refere à inclusão social da criança portadora de necessidades especiais, visto que consideramos a escola como um dos principais locais de socialização da criança.

Nessa perspectiva, salienta-se que a escola é formadora de opiniões e por isso tem responsabilidade sobre os valores de seus educandos. É importante que durante a infância se aprenda a conviver e respeitar as diferenças, sejam elas físicas, sociais, culturais ou espirituais, contribuindo na formação de adultos sem preconceitos, sabedores da necessidade de uma sociedade igualitária e cientes de que cada um possui possibilidades que devem ser estimuladas e desenvolvidas.

Quanto ao envolvimento motor é importante para a escola considerar e respeitar as limitações da escrita e da fala e, nessas situações, encontrar estratégias que possam viabilizar a aprendizagem. É preciso lembrar que qualquer limitação motora pode ser minimizada por meio de recursos didáticos capazes 
de compatibilizar a aprendizagem utilizando meios e instrumentos alternativos, atualmente disponíveis pela engenharia de reabilitação(15)

A Mãe 1 relatou a dificuldade encontrada para que seu filho pudesse acompanhar a rede regular de ensino:

Quando ele começou a ir pro colégio, fazíamos um xeróx ampliado do livro usado pela turma da aula dele, porque ele não conseguia escrever no tamanho do livro normal, mas não deu certo, porque nem com o espaço maior ele conseguia, a falta de coordenação não permitia que ele escrevesse, nem em espaços maiores, nem em menores. Aí a gente ficou sabendo [...] que tinha um teclado especial, que é sensível ao toque, mas ele limpa os movimentos involuntários [...] foi caro prá comprar, mas a gente deu um jeito (Mãe1).

Sabe-se que o recurso tecnológico mencionado pela Mãe 1 existe, assim como outros, porém o que deixa a desejar não é a demanda tecnológica disponível para facilitar a vida das crianças, mas sim a dificuldade de acesso a essas tecnologias, pois essas, geralmente, são financeiramente inviáveis para a população em geral. Isso é possível perceber na fala que segue:

Eu queria comprar um computador para ele, porque já disseram que é muito bom, mas não tenho dinheiro (Mãe 5).

O depoimento da Mãe 5 enfoca a questão financeira como mais uma forma de exclusão social. A dialética da inclusão/exclusão das crianças portadoras de necessidades especiais também pode ser considerada como consequência do desconhecimento por parte das famílias de seus direitos de cidadania. O não acesso ao exercício cidadão de direitos e deveres marginaliza os indivíduos, dicotomizando a sociedade.

Nessa perspectiva, percebe-se que o cuidado à criança e família deve, obrigatoriamente, ultrapassar as ações direcionadas ao físico/biológico adquirindo abrangência. O cuidado à saúde desta população necessita incluir a educação, a fim de conscientizá-los de que são cidadãos, autores de sua história, com direitos de vida digna na sociedade.

O espaço escolar poderia contar com a enfermeira, não apenas para as crianças com necessidades especiais, mas também para trabalhar as questões da saúde, atuando na sua promoção e, mais especificamente, na prevenção de agravos, visto que o fazer da enfermeira deve estar voltado a um cuidado integral do $\operatorname{ser}^{(18)}$. Além disso, com a presença da enfermeira nas escolas seria possível iniciar um processo que objetivasse a diminuição do preconceito para com as pessoas consideradas "diferentes", as que não se enquadram no padrão físico e social estipulado pela sociedade.

Portanto, diminuir os preconceitos, auxiliar na inserção das crianças portadoras de paralisia cerebral na família e na sociedade como um todo, pode ser considerado atribuição da enfermeira, atuando como promotora, educadora e reabilitadora da saúde, permitindo uma melhor qualidade de vida tanto para as crianças quanto para suas famílias.

\section{CONSIDERAÇÕES FINAIS}

A partir do olhar das mães sobre o processo de inserção social de seus filhos, portadores de necessidades especiais decorrentes do diagnóstico da paralisia cerebral, foi possível perceber os medos e anseios por elas experienciados.

A dificuldade de locomoção foi considerada um dos fatores que mais inviabilizam a integração da criança em outros ambientes sociais, além do familiar. A esse fato acrescenta-se a falta de infra-estrutura urbana que limita o livre acesso aos cadeirantes. Sendo assim, acreditamos que ações governamentais, como também as da sociedade privada, poderiam minimizar as restrições de acesso dos portadores de deficiência física e não apenas das crianças com paralisia cerebral.

Outro ponto que deve ser salientado é o ingresso das crianças portadoras de necessidades especiais na rede regular de ensino. É possível perceber uma discrepância entre o Estatuto da Criança e do Adolescente ${ }^{(13)}$, que menciona a obrigatoriedade das escolas regulares estarem aptas para receberem crianças portadoras de necessidades especiais, e a realidade vivenciada pelas famílias. A realidade encontrada provavelmente ocorre porque as escolas regulares de ensino, no contexto estudado, não se encontram estruturadas, seja no que se refere aos recursos físicos como também pela falta de preparo pedagógico por parte dos professores em receber crianças portadoras de necessidades especiais compartilhando o ensino em classes regulares.

Na tentativa da redução dos sentimentos de impotência vivenciados pela família, a enfermeira pode 
atuar como promotora da saúde e poderá, principalmente, auxiliar a família a encontrar maneiras criativas capazes de oferecer estímulos que, progressivamente, possam despertar interesse para prosseguir na conquista de avanços cada vez mais complexos, com a interação e cooperação da família. Além disso, entendemos que a enfermeira como agente de transformação possui a qualificação necessária para incentivar e mobilizar a família no resgate da cidadania, buscando, junto aos órgãos competentes, que as políticas públicas direcionadas às pessoas com necessidades especiais sejam supervisionadas e cumpridas.

\section{REFERÊNCIAS}

1. Mancini MC, Megale L, Brandão MB, Melo APO, Sampaio RF. Efeito moderador do riso social na relação entre risco biológico e desempenho funcional infantil. Rev Bras Saúde Mat Inf. 2004;4(1):25-34.

2. Silva NLP, Dessen MA. Deficiência mental e família : implicações para o desenvolvimento da criança. Psicologia: teoria e pesquisa 2001;17(2):133-41.

3. Levorlino SA. Estudo das percepções, sentimentos e concepções, para entender o luto de familiares de portadores da Síndrome de Down na cidade de Sobral - Ceará [tese]. Ribeirão Preto (SP): Universidade de São Paulo; 2005.

4. Andrade AS, Santos DS, Bastos AC, Pedromônico RM, Almeida Filho N, Barreto AL. Ambiente familiar e desenvolvimento cognitivo infantil: uma abordagem epidemiológica. Rev Saúde Publ. 2005;39(4):606-11.

5. Gripo MLVS. Avaliação de um instrumento de promoção do cuidado da criança a partir da percepção do cuidador familiar [dissertação]. São Paulo (SP): Universidade de São Paulo; 2007.

6. Milbrath MM. Cuidado da família à criança portadora de paralisia cerebral nos três primeiros anos de vida [dissertação]. Rio Grande (RS): Escola de Enfermagem. Fundação Universidade Federal de Rio Grande; 2008.

7. Virvata V. Mídia e deficiência. Brasília: Andi/Fundação Banco do Brasil; 2003.

8. Silva NLP, Dessen MA. Crianças com síndrome de Down e suas implicações familiares. Psicol Reflexão e Crítica. 2003;16(3):503-14.

9. Yano AMM. As práticas de educação em famílias de crianças com paralisia cerebral diplégica espástica e com desenvolvimento típico pertencentes a camadas populares da cidade de Salvador [tese]. Ribeirão Preto (SP): Universidade de São Paulo; 2003.

10. Vieira MA, Lima RGA. Crianças e adolescentes com doenças crônicas convivendo com mudanças. Rev Latino-Am Enferm. 2002;10(4):552-60.

11. Minayo MC. O desafio do conhecimento: pesquisa qualitativa em saúde. $7^{\mathrm{a}}$ ed. Rio de Janeiro: Hucitec; 2000.

12. Araújo RCT, Omote S. Atribuição de gravidade à deficiência física em função da extensão do acometimento e do contexto escolar. Rev Bras Educ Espec. 2005;11(2):241-54.

13. Estatuto da Criança e do Adolescente. Lei $N^{\circ} 8.069$, de 13 de Julho de 1990. [página na Internet]. Brasília; 1990 [acesso 2006 Jun 22]. Disponível: http://www.mj.gov.br/ sedh/dca/eca.htm.

15. Instituto Sarah Kubicheck : paralisia cerebral [página na Internet]. Brasília, 2006 [acesso em 2006 Fev 20]. Disponível: http://www.sarahkubichek.com.br.

16. Milbrath VM, Soares DC, Cecagno D, Vieira AC, Siqueira HCH. O brincar da criança com paralisia cerebral: em olhar da enfermeira. Rev Enferm Atual. 2007;7(42):21-4.

17. Estatuto da Pessoa Portadora de Deficiência. Lei n. 7.853, de 24 de outubro 1989. [acesso em 2007 Mar 05]. Disponível: http://www6.senado.gov.br/sicon/ ListaReferencias.action?codigobase=2\&codigoDocum ento=133254.

18. Brandalize D, Zagonel IPS. Um marco conceitual para o cuidado ao familiar da criança com cardiopatia congênita à luz da teoria de Roy. Cogitare Enferm. 2006 Set/ Dez;11(3):264-70. 